\title{
Peran Komunitas Arthropoda Tanah dalam Upaya Pelestarian Agroforestri Berbasis Sengon dengan Tanaman Budidaya Porang (Amorphopallus muelleri Blumei)
}

\section{(Role of Arthropodes Community in Effort Sengon Based Agroforestri Preservation Plants of Porang Culture (Amorphopallus muelleri Blumei))}

\author{
Fujianor Maulana \\ Jurusan Pendidikan Biologi, STKIP PGRI Banjarmasin \\ maulana.stkipbjm@gmail.com
}

\begin{abstract}
ABSTRAK
Konversi penggunaan lahan mengubah hutan dan pengelolaan lahan yang buruk telah merusak ekosistem hutan. Secara otomatis mengganggu komponen dalam ekosistem hutan, antara lain arthropoda tanah. Oleh karena itu, diperlukan sistem pengelolaan lahan ramah lingkungan. Salah satu sistem tersebut adalah Agroforestri berbasis Sengon dengan Budidaya Porang. Tujuan penelitian adalah memahami struktur dan fungsi artropoda tanah di tanah Porang dan non-Porang. Penelitian dilakukan di KPH Saradan, Kabupaten Madiun. Dua lokasi dipilih, lahan Agroforestri dengan budidaya Porang dan lahan Agroforestri non-Porang. Metode penelitian adalah survei observasional. Teknik pengambilan sampel terhadap Arthropod adalah Pitfall Trap. Hasil penelitian menunjukkan bahwa keanekaragaman keluarga Arthropoda tanah di tanah Porang dihitung menjadi 27 keluarga, sedangkan di tanah non-Porang, diperkirakan 30 keluarga Arthropoda tanah diperkirakan. Indeks Keragaman Shannon-Wienner di tanah non-Porang berada dalam kategori rendah dengan $H>1$ (1,32), sedangkan indeks keanekaragaman di tanah Porang berada dalam kategori sangat rendah dengan $H<1(0,83)$. Indeks Bray-Curtis, yang mengukur kesamaan dua komposisi komunitas tanah di tanah Porang dan non-Porang, dihitung hingga 0,91, dengan kategori tidak berbeda. Komunitas artropoda tanah di tanah Porang memainkan beberapa peran seperti pengurai tanah (57\%), trafo serasah (22\%), dan predator (21\%). Peran trafo serasah dan pemangsa memiliki tingkat yang sama (26\%).
\end{abstract}

Kata kunci: Arthropoda, tanah, agroforestri, porang.

\section{ABSTRACT}

Land-use change forest conversion and poor land management have damaged forest ecosystem. It is automatically disturbing the components in the forest ecosystem, among other soil arthropods. Therefore, environmental friendly land management system is required. One such system is Sengon-based Agroforestry with Porang Cultivation. The objective of research is (1) to understand the structure and function of soil arthropods in the Porang and non-Porang lands; Research is conducted at KPH Saradan, Madiun Regency. Two locations are chosen, Agroforestry land with Porang cultivation and non-Porang Agroforestry land. Method of research is observational survey. Sampling technique toward Arthropod is Pitfall Trap. Result of research indicates that the diversity of soil Arthropods family in the Porang land is counted to 27 families, while in the non-Porang land, 30 families of soil Arthropods are estimated. Shannon-Wienner Diversity Index in the non-Porang land is in low category with H>1 (1.32), while the diversity index in the Porang land is in very low category with $H<1$ (0.83). Bray-Curtis Index, which is measuring the similarity of two compositions of land community in the Porang and non-Porang lands, is counted to 0.91, submitting to the category of not different. The community of land Arthropods in the Porang land plays some roles such as soil decomposer (57\%), litter transformer (22\%), and predator (21\%). The roles of litter transformer and predator have similar rate (26\%).

Keywords: Arthropods, soil, agroforestry, porang.

\section{PENDAHULUAN}

Kerusakan hutan merupakan salah satu masalah yang sekarang ini sering melanda Indonesia. Indonesia sebagai salah satu negara kepulauan memiliki banyak hutan, tetapi sekarang ini kerusakan hutan Indonesia sangat tinggi. Pengalihan fungsi hutan merupakan salah satu kerusakan yang terjadi di Indonesia, hutan diubah menjadi 
lahan pertanian, perumahan dan sebagainya. Berbagai pengalihan fungsi hutan tersebut menyebabkan kerusakan ekosistem hutan yang telah lama terbentuk. Pengalihan fungsi hutan tersebut menyebabkan berbagai bencana alam, seperti erosi, tanah longsor, banjir, kekeringan dan bahkan perubahan lingkungan global. Selain itu, banyak masalah seperti penurunan kesuburan tanah, tingkat biodiversitas lahan menurun, serta kepunahan flora dan fauna. Masalah ini bertambah berat dari waktu ke waktu sejalan dengan meningkatnya pengalihan fungsi hutan yang diubah menjadi lahan usaha lain padahal dengan adanya kelestarian hutan sama halnya dengan pelestarian kehidupan makhluk hidup.

Keanekaragaman makrofauna tanah salah satunya Arthropoda dan fungsi ekosistem menunjukkan hubungan yang sangat kompleks dan belum banyak diketahui, serta perhatian untuk melakukan konservasi terhadap keanekaragaman hewanhewan makrofauna tanah masih sangat terbatas (Lavelle et. al., 1994). Alih guna lahan hutan menjadi area pertanian atau peruntukan lainnya cenderung menurunkan biodiversitas makrofauna tanah. Oleh karena itu perlu alternatif sistem penggunaan lahan untuk konservasinya.

Perubahan ekosistem hutan menjadi ekosistem binaan diketahui memberikan pengaruh yang signifikan terhadap diversitas Arthropoda. Perubahan komposisi Arthropoda akibat aktivitas manusia telah dilaporkan dalam beberapa penelitian.Perubahan komposisi ini diyakini dapat mengganggu keseimbangan lingkungan karena komposisi baru biasanya didominasi oleh fauna dari daerah lain yang mendesak keberadaan fauna lokal, perubahan komposisi Arthropoda tanah juga dapat diikuti oleh perubahan komposisi hewan maupun tumbuhan yang secara langsung maupun tidak langsung saling berinteraksi (Leksono et. al., 2005;2008).

Kerusakan hutan ini mendorong manusia untuk mencari solusi dari permasalahan ini dan berupaya mengurangi dan menanggulangi permasalahan tersebut Oleh karena itu, munculah suatu sistem pertanian yang disebut Agroforestri.
Agroforestri ini merupakan suatu sistem pertanian dengan mengkombinasikan beberapa komponen tanaman hutan dengan tanaman pertanian, dimana sistem ini bertujuan untuk memperbaiki kondisi lahan, pelestarian lingkungan, serta meningkatkan kesejahteraan masyarakat.

Dalam pengelolaan hutan secara Agroforestri didalamnya juga diharapkan adanya usaha proses diversifikasi pangan yang berorientasi terhadap sumberdaya lokal, yang artinya bisa dijadikan sebagai pemenuhan pangan dan juga dapat menjadi alternatif peningkatan kesejahteraan ekonomi bagi masyarakat tersebut, Salah satu alternatif yang dapat dipilih untuk program diversifikasi pangan ini adalah dengan membudidayakan tanaman porang dalam ekosistem hutan Agroforestri, tanaman ini merupakan tanaman daerah tropis yang termasuk famili iles-iles yang memiliki umbi dengan kandungan glukomanan cukup tinggi. Tanaman ini memiliki potensi yang besar untuk dijadikan sebagai komoditi ekspor penting di Jawa Timur dan juga dapat menjadi pemasok bahan baku untuk indutri lokal. Zat glukomanan dapat dimanfaatkan sebagai bahan perekat, mie, konyaku-jelly, perekat tablet, pembungkus kapsul, penguat kertas, bahan peledak, kosmetik dan pembersih (Romli, 2002).

Walaupun penelitian fauna tanah sudah dilakukan di beberapa kawasan konservasi di Indonesia, antara lain serangga serasah di Kebun Raya Bogor (Suhardjono 1998), serangga tanah pada beberapa tipe habitat hutan (Mercianto et. al., 1997), namun secara umum dapat dikatakan bahwa jumlahnya sangat sedikit. Sistem pengelolaan lahan merupakan faktor kunci dalam konservasi artropoda tanah oleh karena itu perlunya dilakukan inventarisasi serta bagaimana struktur komunitas Arthropoda antara lahan yang telah dilakukan budidaya dengan lahan yang tidak dibudidayakan agar dapat diketahui sejauh mana pengaruhnya terhadap kelestarian komunitas Arthropoda serta perlunya informasi bagaimana pengaruhnya dalam menjaga kelestarian ekosistem yang ada didaerah mereka. Tujuan penelitian adalah 
memahami struktur dan fungsi artropoda tanah di tanah Porang dan non-Porang.

\section{METODE PENELITIAN}

Penelitian ini dilakukan di wilayah Agroforestri KPH Saradan tepatnya di desa Sumber Bendo kecamatan Saradan Kabupaten Madiun. Lokasi penelitian terdiri atas 2 lokasi yaitu lokasi pertama adalah wilayah Agroforestri yang terdapat tanaman budidaya Porang dan lokasi kedua adalah wilayah Agroforestri non Porang.

Penelitian ini merupakan penelitian terhadap kawasan Agroforestri yang terdapat tanaman budidaya Porang dengan menggunakan pendekatan lingkungan (struktur komunitas Arthropoda). Metode yang digunakan dalam penelitian struktur komposisi Arthropoda tanah adalah menggunakan metode observasional dengan menggunakan rancangan blok. Untuk pencuplikan arthopoda tanah dilakukan dengan menggunakan metode perangkap jebak (pitfall trap) berdasarkan pedoman sampling standar IBOY (Internasional Biodiversity Observation Year) untuk pemasangan botol jebak dilakukan pada waktu pagi hari, pemasangan ini dilakukan pada dua lokasi berbeda lokasi pertama yaitu lahan Agroforestri Sengon yang terdapat budidaya Porang sedangkan lokasi yang kedua yaitu lahan Agroforestri Sengon yang tidak dibudidayakan Porang, masing-masing lokasi dipasang 15 botol jebak jadi jumlah keseluruhan botol jebak yaitu 30 buah.

Untuk pemasangan jebakan Pitfall trap hal yang pertama yang dilakukan adalah dengan membagi lokasi penelitian menjadi 3 buah garis transek kemudian disetiap tiap garis transek dipasang botol jebak sebagai titik sampling, tiap garis transek dipasang 5 buah botol jebak dengan perkiraan jarak antar titik sampling sekitar 5 - 6 meter. Setelah titik sampling ditentukan selanjutnya dipasang botol jebak dengan mengisi terlebih dahulu botol jebak dengan larutan formalin $4 \%$ yang sudah dicampur dengan sedikit larutan deterjen setinggi $1,5-2 \mathrm{~cm}$ kemudian ditanam dalam tanah dengan bibir botol sejajar dengan permukaan tanah lalu diberi pelindung pada bagian atasnya.

\section{Analisis Data}

Untuk paramater yang digunakan untuk membandingkan komunitas Arthropoda adalah nilai penting, kesamaan dan diversitas. Variable yang diukur adalah kelimpahan relatif dan frekuensi relatif. Diversitas pada setiap lokasi dihitung dengan indeks Shannon-Wienner (H'). Tingkat kesamaan komposisi dianalisis dengan indeks Bray-Curtis.

1. Kelimpahan

$=\frac{\text { Jumlah total Individu suatu jenis }}{\text { Luas total daerah yang di sampling }}$

2. $\mathrm{KR}(\%)$

$$
=\frac{\text { Kelimpahan suatu jenis }}{\text { Kelimpahan seluruh jenis }} \times 100
$$

3. Frekuensi

$=\frac{\text { Jumlah plot suatu jenis }}{\text { Jumlah total plot pengamatan }}$

4. $\operatorname{FR}(\%)$

$=\frac{\text { Frekuensi suatu jenis }}{\text { Frekuensi seluruh jenis }} \times 100$

5. Indeks Nilai Penting (INP)

$=\mathrm{KR}+\mathrm{FR}$

Diversitas pada setiap lokasi dihitung dengan indeks Shannon-Wienner ( $\left.\mathrm{H}^{\prime}\right)$. Digunakan rumus sebagai berikut (Krebs, 2001):

$$
H^{\prime}=-\sum_{\mathbf{i}=1}^{\mathbf{n}}\left[\frac{\mathbf{n}_{\mathbf{i}}}{\mathbf{N}} \log \frac{\mathbf{n}_{\mathbf{i}}}{\mathbf{N}}\right]
$$

Keterangan :

$H^{\prime}=$ Indeks Keanekaragaman ShannonWiener

$\mathrm{Ni}=$ Jumlah individu jenis ke-n

$\mathrm{N}=$ Total jumlah individu

Nilai $H^{\prime}$ berkisar antara $1-4$

$H^{\prime}<1$ :Sangat rendah

$H^{\prime}>1-2$ : keanekaragaman rendah

$\mathrm{H}^{\prime}>2-3$ :Sedang (medium)

$\mathrm{H}^{\prime}>3-4$ : Keanekaragaman tinggi

$\mathrm{H}^{\prime}>4$ : Sangat tinggi.

(Barbour et al. 1987)

Untuk tingkat kesamaan komposisi antara dua lokasi dianalisis dengan indeks Bray-Curtis. Digunakan rumus sebagai berikut (Brower, et al., 1990) : 


$$
\boldsymbol{I B C}=\mathbf{1}-\frac{\sum_{\mathbf{i = 1}}^{\mathbf{n}}\left|\mathbf{n}_{\mathbf{i k}}-\mathbf{n}_{\mathbf{i j}}\right|}{\sum_{\mathbf{i}=\mathbf{1}}^{\mathbf{n}}\left(\mathbf{n}_{\mathbf{i k}}-\mathbf{n}_{\mathbf{i j}}\right)}
$$

Keterangan :

IBC $=$ Koefisien kesamaan komposisi

Nik = Jumlah Individu pada spesies ke- $\mathrm{i}$ di lokasi 1

Nij = Jumlah Individu pada spesies ke- $\mathrm{i}$ di lokasi 2

$\mathrm{N} \quad=$ Jumlah spesies dalam sampel

Kelimpahan dan kekayaan populasi Arthropoda tanah dibandingkan antar lokasi dan waktu dengan metode model linier umum (general linear model), analisis variansi (analysis of variance). Hasil uji yaitu F-statistik dianggap berbeda nyata pada $\mathrm{P}<0.05$. Untuk perhitungan statistik menggunakan program excel 2007 dan SPSS $®$ versi 16,0 .

Untuk skala pengukuran persepsi masyarakat menggunakan jawaban dari responden dari hasil wawancara menggunakan skala Likert dimana skor tertinggi diberi skor 5 dan untuk bobot terendah memperoleh skor 1, beberapa alternatif pilihannya, sangat setuju (nilainya 5), setuju (nilainya 4), netral (nilainya 3 ), tidak setuju (nilainya 2), sangat tidak setuju (nilainya 1) (Sumarmi, 2006).

\section{HASIL DAN PEMBAHASAN}

\section{Kelimpahan Arthropoda Tanah Pada} Lahan Budidaya Porang dan non Porang

Berdasarkan hasil penelitian jumlah keseluruhan individu Arthropoda tanah yang didapat pada lahan Agroforestri Sengon Buto
(Enterolobiun cyclocarpum) dengan menggunakan jebakan pitfall trap pada dua lahan yang berbeda yaitu lahan budidaya Porang dan lahan non budidaya Porang adalah sebesar 5835 individu yang terdiri dari 14 ordo dengan 36 famili. Untuk kelimpahan Arthropoda tanah pada lahan dengan budidaya Porang sebesar 3186 individu, jumlah tersebut lebih tinggi dibandingkan jumlah Arthropoda tanah yang didapat pada lahan non porang yaitu sebesar 2670 individu.

Kelimpahan pada dua lokasi penelitian terdapat perbedaan untuk lahan budidaya Porang kelimpahan famili Arthropoda tertinggi diperoleh Formicidae dengan jumlah 2638 individu, dilanjutkan famili Gryllidae 209 individu, Larva Lepidoptera 120 individu, Araneidae 82 individu, sedangkan untuk kelimpahan Arthropoda tanah pada lahan non Porang ditempati oleh famili Formicidae 1779 individu, Larva Lepidoptera 289, Gryllidae 221 dan Araneida 96 individu.

Kelimpahan famili Arthropoda dengan jumlah individu yang tinggi dari suatu famili Arthropoda tanah menyebabkan adanya famili yang mendominasi pada habitat tersebut, famili Arthropoda tanah yang mendominasi pada lahan Porang dan lahan non Porang dapat menggunakan indeks nilai penting (INP). Pada kedua lokasi penelitian famili Formicidae menempati dominansi tertinggi famili Gryllidae kemudian diikuti Larva Lepidoptera, Araneidae, Xiphydriidae, Cylisticidae, dan Coccinellidae.

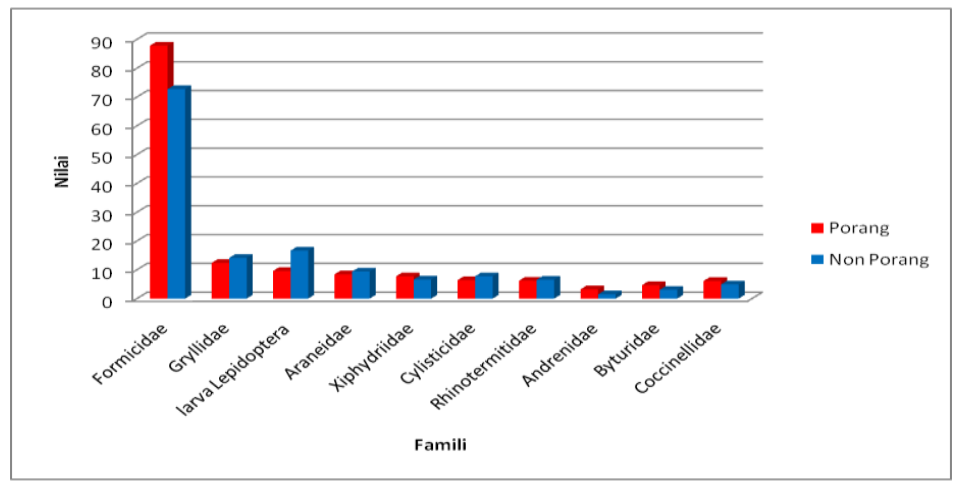

Gambar 1. Perbandingan nilai INP antar famili Arthropoda tanah pada lahan Porang dan non Porang. 
Kelimpahan famili antar lokasi penelitian untuk famili formicidae pada lahan Porang lebih tinggi dibandingkan pada lahan non Porang akan tetapi untuk kelimpahan famili Arthropoda yang lain kelimpahan jumlah individu lebih tinggi pada lahan non Porang, hal ini dapat terjadi karena adanya perbedaan tingkat kerapatan vegetasi pada lahan Porang dengan lahan yang non Porang, selain itu pengaruh dari aktifitas petani dalam pengelolaan lahan tanaman budidaya seperti penyemprotan pestisida serta pembersihan tanaman liar (penyiangan) disekitar tanaman budidaya ikut mempengaruhi terhadap kelimpahan Arthropoda tanah, karena beberapa jenis tanaman liar (gulma) bermanfaat bagi parasitoid dan predator, karena gulma dapat digunakan tempat berlindung serangga inang dan tempat bertelur bagi parasitoid dan predator.

Hasil indeks diversitas ShannonWienner menunjukkan bahwa indeks diversitas komunitas Arthropoda tanah pada lahan Porang lebih rendah dibandingkan pada lahan Porang yaitu dengan nilai sebesar 0,83 sedangkan nilai indeks diversitas untuk lahan dengan budidaya non Porang sebesar 1,32.



Gambar 2. Perbandingan nilaiindeks Shannon-Wienner antar lahan Porang dan non Porang.

Dari hasil perhitungan indeks diversitas (Gambar 2) maka dapat diketahui bahwa diversitas famili Arthropoda tanah untuk lahan dengan budidaya Porang masuk dalam kategori sangat rendah $\left(\mathrm{H}^{\prime}<1\right)$ sedangkan untuk lahan non Porang termasuk dalam kategori rendah ( $\left.\mathrm{H}^{\prime}>1-2\right)$.

Keadaan masih rendahnya diversitas Arthropoda tanah dari kedua lahan penelitian ini selain karena adanya aktivitas masyarakat dalam pengolahan lahan pertanian yang kurang memperhatikan aspek lingkungan serta dipengaruhi juga oleh faktor lingkungan yang ada dan juga keragaman komponen yang menyusun ekosistem Agroforestri masih rendah.

Menurut Barbour et. al., (1987) keanekaragaman jenis yang tinggi merupakan indikator dari kemantapan atau kestabilan suatu lingkungan pertumbuhan. Kestabilan yang tinggi menunjukkan tingkat kompleksitas yang tinggi, hal ini disebabkan terjadinya interaksi yang tinggi pula sehingga akan mempunyai kemampuan lebih tinggi dalam menghadapi gangguan terhadap komponen-komponen komunitas dalam lingkungannya.

Berdasarkan hasil uji statistik untuk faktor lokasi terhadap keanekaragaman famili Arthropoda tanah secara statistik berbeda nyatahal ini menunjukan adanya pengaruh habitat dalam mendukung diversitas famili Arthropoda tanah, pada lahan non Porang jenis vegetasi lebih rapat, sehingga jumlah jenis vegetasi yang tinggi dapat dihubungkan dengan ketersediaan nutrisi bagi Arthropoda tanah. Semakin banyak ketersediaan makanan, maka semakin beragam pula Arthropoda yang dapat berkembang di habitat tersebut, pada lahan Porang aktivitas petani dengan melakukan penyiangan gulma serta penyemprotan pestisida disekitar tanaman Porang. Menurut Leksono (2008), semakin tinggi tingkat keanekeragaman, semakin kompleks interaksi yang mungkin terjadi antar spesies.

Untuk waktu pencuplikan Arthropoda tanah pada kedua lokasi penelitian terdapat pengaruh variasi temporal untuk famili Cocinellidae pada waktu pencuplikan pertama dimana jumlah kelimpahannya lebih 
tinggi pada lokasi pada lahan non Porang dibandingan pada lahan Porang, diduga adanya perbedaan ini karena famili ini menyukai habitat pada lahan non Porang yang memiliki kerapatan vegetasi yang lebih rapat dikarenakan famili ini bersifat predator ditambah famili ini memiliki mobilitas pergerakan yang tinggi dalam mencari makan sehingga memerlukan tempat yang cocok untuk berkembang biak dan mencari mangsa untuk sumber makanannya.

Tingkat kesamaan komposisi diversitas famili Arthropoda tanah antara lahan budidaya Porang dan lahan non Porang menggunakan nilai dari indeks Bray Curtis (IBC), berdasarkan hasil perhitungan indeks Bray-Curtis kesamaan antara dua komposisi penyusun komunitas lahan budidaya porang dan non budidaya porang adalah sebesar 0.91Komposisi Arthropoda tanah adalah tidak berbeda (serupa) antar dua lokasi lahan budidaya porang dan non budidaya porang.

Perbedaan kondisi makro maupun mikro pada masing-masing habitat, penutupan tanah oleh vegetasi dan penetrasi sinar matahari, yang diterima ekosistem merupakan faktor penentu penting produktifitas primer, yang pada gilirannya dapat mempengaruhi keragaman spesies dan siklus hara (Mokany et al., 2008).

Dengan adanya perbedaan kandungan unsur hara antar lokasi maka terjadilah perbedaan tingkat kesuburan antara lokasi yang satu dengan yang lainnya. Perbedaan yang ada ini dimungkinkan dapat berpengaruh terhadap kemampuan tanaman budidaya untuk dapat tumbuh di lokasi tersebut.
Dari hasil kelimpahan serta diversitas Arthropoda tanah yang terdapat pada lahan dengan budidaya Porang dan lahan non Porang kemudian dapat dilihat kontribusi dari komunitas Arthropoda tanah melalui peran ekologisnya bagi kelestarian Agroforestri yang meliputi peran sebagai soil dekomposer, litter transformer dan predator, yang mana dari fungsi ekologis ini nantinya akan memegang peranan penting dalam siklus hara di dalam tanah, perbaikan struktur tanah dengan meningkatkan porositas dan aerasi tanah sehingga dalam jangka panjang sangat mempengaruhi keberlanjutan produktivitas lahan pertanian.

Arthropoda tanah mempunyai peranan penting dalam dekomposisi bahan organik tanah dalam penyediaan unsur hara, hewan tersebut akan meremah-remah substansi nabati yang mati, kemudian bahan tersebut akan dikeluarkan dalam bentuk feses, kontribusi Arthropoda tanah dalam proses dekomposisi dilihat adanya hubungan yang kuat antara kesuburan tanah, jumlah dan biomassa dari hewan tersebut selain itu juga dapat menjadi bioindikator, meningkatkan porositas dan aerasi tanah (Musyafa, 2005; Rahmawati, 2004; Suhardjono et al, 1998).

Peran komunitas dari Arthropoda tanah sebagai litter transformer dan predator erat kaitannya dengan aktivitas hidup dari Arthropoda tanah itu sendiri yaitu pola makan Arthropoda tanah yang berkaitan dengan apa yang dimakan dan bagaimana memakannya merupakan penentu bagi peranan Arthropoda tersebut, makanan bagi Arthropoda dapat berupa organisme lain baik yang berasal dari tumbuhan maupun hewan.

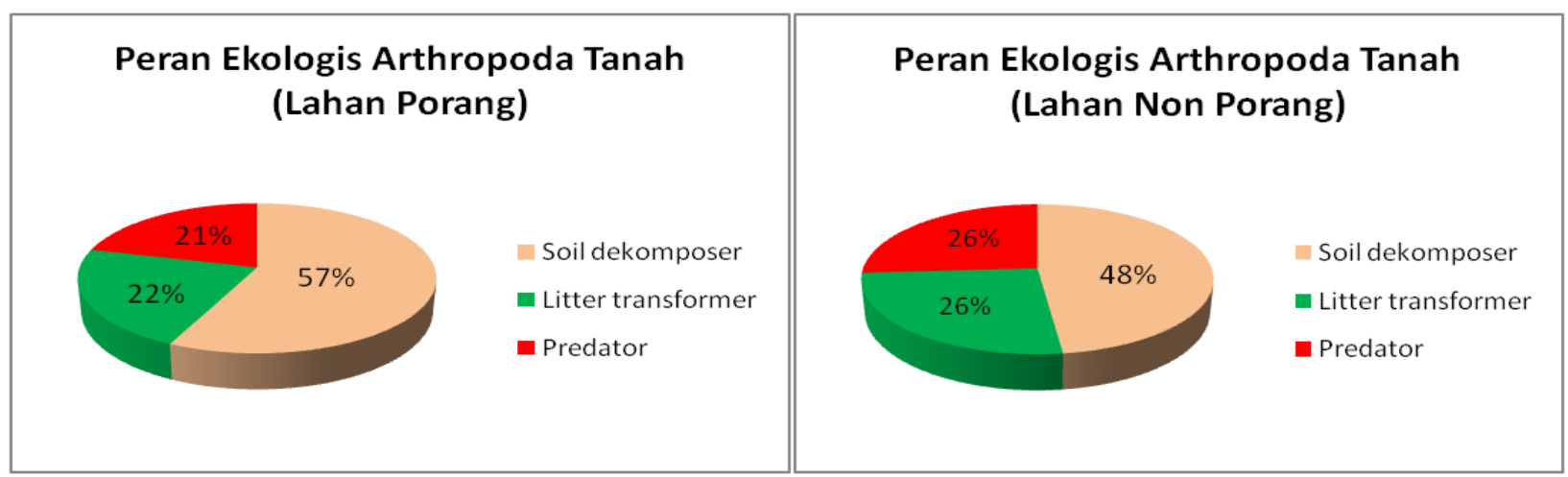

Gambar 3. Diagram peranan ekologis Arthropoda tanah pada lahan Porang dan non Porang 
Dari komposisi komunitas Arthropoda tanah berdasarkan dari peran ekologisnya menunjukkan bahwa terdapat dominasi dari soil dekomposer pada kedua lokasi penelitian, keberadaan dari famili Arthropoda tanah dengan peran sebagai soil dekomposer pada lahan budidaya Porang lebih tinggi dibandingkan dengan lahan non Porang hal ini menunjuk apabila terjadi proses dekomposisi maka prosesnya akan terjadi lebih cepat dibandingkan pada lahan non Porang, proses dekomposisi bahan organik baik itu yang berasal dari hewan maupun tumbuhan (serasah) akan bermanfaat untuk kesuburan dan memperbaiki struktur tanah pada lahan budidaya Porang. Hal ini sesuai dengan yang diungkapkan Wallwork (1976) bahwa kebanyakan hewan Arthropoda tanah merupakan hewan-hewan penggali tanah, terutama dari kelompok serangga yang hidup di bawah seresah tumbuhan dan aktif memperbaiki struktur tanah.

Dari hasil penelitian keberadaan Arthropoda tanah yang berperan sebagai litter transformer dan predator lahan non Porang lebih tinggi dibandingkan pada lahan Porang, hal ini disebabkan stabilitas keragaman famili dan struktur komposisi vegetasi pada lahan non Porang lebih baik dibandingkan pada lahan Porang hal ini nantinya akan terkait dengan ketersediaan sumber makanan bagi Arthropoda.

Pada lahan budidaya Porang dengan adanya aktivitas pengolahan lahan secara intensif oleh petani sehingga menyebabkan ketersediaan seresah sebagai penutup tanah jumlahnya lebih sedikit dibandingkan pada lahan non Porang yang tidak mendapat perlakuan pengolahan lahan, hal ini juga menjadi salah satu faktor yang mempengaruhi keberadaan komunitas Arthropoda tanah pada lahan dengan budidaya Porang.

\section{KESIMPULAN}

Komunitas Arthropoda tanah memegang peranan penting bagi kelestarian ekosistem Agroforestri serta lahan pertanian budidaya Porang, baik itu perannya sebagai predator, soil decomposer maupun litter transformer, karenanya keberadaan dari Arthropoda tanah harus tetap dilestarikan dan dilindungi agar stabilitas dilingkungan tetap terjaga, persepsi masyarakat yang masih rendah terhadap pentingnya keberadaan dari komunitas Arthropoda tanah tersebutdan masih kurangnya pengetahuan masyarakattentang manfaat dari komunitas Arthropoda tanah menyebabkan aktivitas masyarakat dalam pengolahan lahan tanaman budidaya cenderung tidak ramah lingkungan dan dapat mengganggu dan merusak komponen-komponen yang menyusun ekosistem Agroforestri.

\section{DAFTAR PUSTAKA}

Barbour, M. G., J.H. Burk., and W.P. Pitts. 1987. Terrestrial Plant Ecology. The Benjamin/Cumming Publishing Company Ins, California.

Brower, J. E., J. E. Zar C. N. Von Ende. 1990. Field and Laboratory Methods for General Ecology. Third Edition. Wm.C. Brown Publisher, Dubuque.

Krebs, C.J. 2001. Ecology: The Experimental Analysis of Distribution and Abundance. 5th ed. Benjamin Cummings. Menlo Park, California.

Lavelle, P.1994. Soil fauna and sustainable land use in the humid tropics. In D.I.Greenland and I Szabolcs (eds) Soil Resiliense and Sustainable land use. CAB International. Oxon.

Leksono, A.S., N. Nakagoshi and Y. Isagi.(2005). The of forest distrubance on flying insect assemblages in Trawas, East Java. Tropics 14 (4) 335-343

Leksono, A. S, Penatagama Z. Dan Rahardi, B. 2008. Pemetaan vegetasi pepohonan dan serangga kanopi di kawasan konservasi sekitar Desa Ranupani, Kab. Lumajang. Jurnal Ilmu-ilmu Hayati.

Mercianto, Y., Yayuk R. S. dan Dedy D. 1997 . Perbandingan populasi serangga tanah pada tiga 

keanekaragaman
tegakan
Dipterocarpaceae.
Prosiding
Seminar Biologi XIV dan Kongres
Nasional Biologi XI. Perhimpunan
Biologi Indonesia Cabang Jakarta.
Depok. Hal : 86-89.

Monkany, A. J.T. Wood and S.A. Cunningham. 2008. Effect of shade and shading history on spesies abundances and ecosystem processes in temporary pounds. Freshwater Biology.53(10): 19171928.

Musyafa (2005). Peranan makrofauna tanah dalam proses dekomposisi serasah Acacia mangium. Biodiversitas 6(1): 63-65.

Rahmawaty. 2004. Studi keanekaragaman mesofauna tanah di kawasan hutan wisata alam Sibolangit. Universitas Sumatera Utara.

Romli, H.U. 2002 Hutan lestari berkat tanaman Porang. Http : // www. pikiranrakyat .com (Tanggal akses 27 Desember 2010).

Suhardjono, Y.R. 1998. Serangga serasah: keanekaragaman takson dan perannya di Kebun Raya Bogor. Biota Vol.III (1):16-24.

Sumarmi. 2006. Botani dan tinjauan gizi jamur tiram putih. Jurnal Inovasi Pertanian, Volume 4, No.2 Halaman 124-130.

Wallwork, J.A. 1976. The Distribution and Diversity of Soil Fauna. Academic Press. Inc. 